\title{
Familial sarcoidosis terminating as neurosarcoidosis
}

\author{
R. SALM \\ M.D., F.C.Path. \\ Department of Histopathology, \\ Royal Cornwall Hospital (Treliske), Truro, Cornwall
}

\begin{abstract}
Summary
A case of sarcoidosis is recorded in a 27 -year-old male, whose elder sister has also been suffering from sarcoidosis.

The disease was characterized by involvement of the mucosa of the upper respiratory tract, gross transient peripheral lymphadenopathy and terminal neurosarcoidosis, death being due to an acute obstructive hydrocephalus.
\end{abstract}

\section{Introduction}

Sarcoidosis is a systemic disease with numerous manifestations and modes of presentation. Amongst the rarer aspects are: (1) familial incidence, (2) transient generalized lymphadenopathy, (3) involvement of the mucous membrane of the upper respiratory tract, and (4) involvement of the central nervous system (CNS). Detailed necropsy findings in cases of neurosarcoidosis have been recorded comparatively infrequently. The following case is reported as a full necropsy was carried out and as a combination of all four of the above features was observed which, it is believed, has not been noted before.

\section{Case report}

J.M., a farm labourer, was first seen in May 1964, aged 27 years, with erythema nodosum, pyrexia, malaise and lassitude. A chest radiograph showed bilateral hilar lymphadenopathy, but the lung fields were clear and liver and spleen were impalpable, and remained so throughout his illness. There was no dyspnoea, and respiratory function tests were normal and remained so. The ESR was $8 \mathrm{~mm}$ after $1 \mathrm{hr}$ and the Mantoux reaction (1:100 O.T.) was negative. Biopsy of one of the bilaterally enlarged epitrochlear lymph glands (64/1601) confirmed the clinical diagnosis of sarcoidosis.

During 1964 the peripheral (submandibular, cervical, axillary, epitrochlear, inguinal and popliteal) as well as the right paratracheal lymph glands became grossly enlarged. The submandibular and epitrochlear lymph glands reached such proportions that they caused difficulty in chewing and in extending the elbows.
In the course of the following year the enlargement of the peripheral lymph glands slowly regressed and finally they became impalpable, but towards the end of 1965 bilateral nasal obstruction developed associated with a troublesome discharge. Histological examination $(66 / 407)$ of the nasal mucosa showed the presence of sarcoid granulomata. The obstruction improved with application of cortisone cream.

From September 1966 onwards the patient developed symptoms indicative of CNS involvement: intermittent headaches, diplopia due to intermittent strabismus, mild cerebellar ataxia, some intellectual dulling, and attacks of drowsiness and mental con fusion. Prednisolone was given in a daily dose of $30 \mathrm{mg}$, though with little clinical benefit. Polyuria was now noted, but since the urine concentration and water deprivation tests were normal, the serum calcium normal at $5.2 \mathrm{mEq} / 1(9.2 \mathrm{mg} / 100 \mathrm{ml})$ and the urinary calcium excretion slightly raised to $17.7 \mathrm{mEq}(400 \mathrm{mg})$ in $24 \mathrm{hr}$, it was thought that the polyuria was not due to diabetes insipidus but to a disorder of the calcium metabolism. In spite of an excellent ventilatory capacity the patient's $\mathrm{PCO}_{2}$ was always found to be raised (varying between 55 and $60 \mathrm{~mm}$ ), probably due to hypothalamic involvement, an interpretation which was supported by the EEG tracings. The CSF showed a raised protein content (up to $465 \mathrm{mg} / 100 \mathrm{ml}$ terminally) without any increase in cells. The CSF pressure was raised to $220 \mathrm{~mm}$. Attacks of amnesia and confusion increased in frequency. The patient was admitted in a comatose condition in April 1967 with a blood sugar of $440 \mathrm{mg}$ / $100 \mathrm{ml}$, tachycardia and tachypnoea, and he died within a few hours of admission, 3 years after the onset of the malady.

\section{Necropsy (P.M. 67/72)}

The body was that of a well-nourished young male, measuring $179 \mathrm{~cm}$ in length and weighing $80.6 \mathrm{~kg}$, of Cushingoid appearance. The heart was hypertrophied, weighing $410 \mathrm{~g}$. There was a mucous bronchitis, but the lungs, apart from congestion, were normal. None of the peripheral lymph glands 


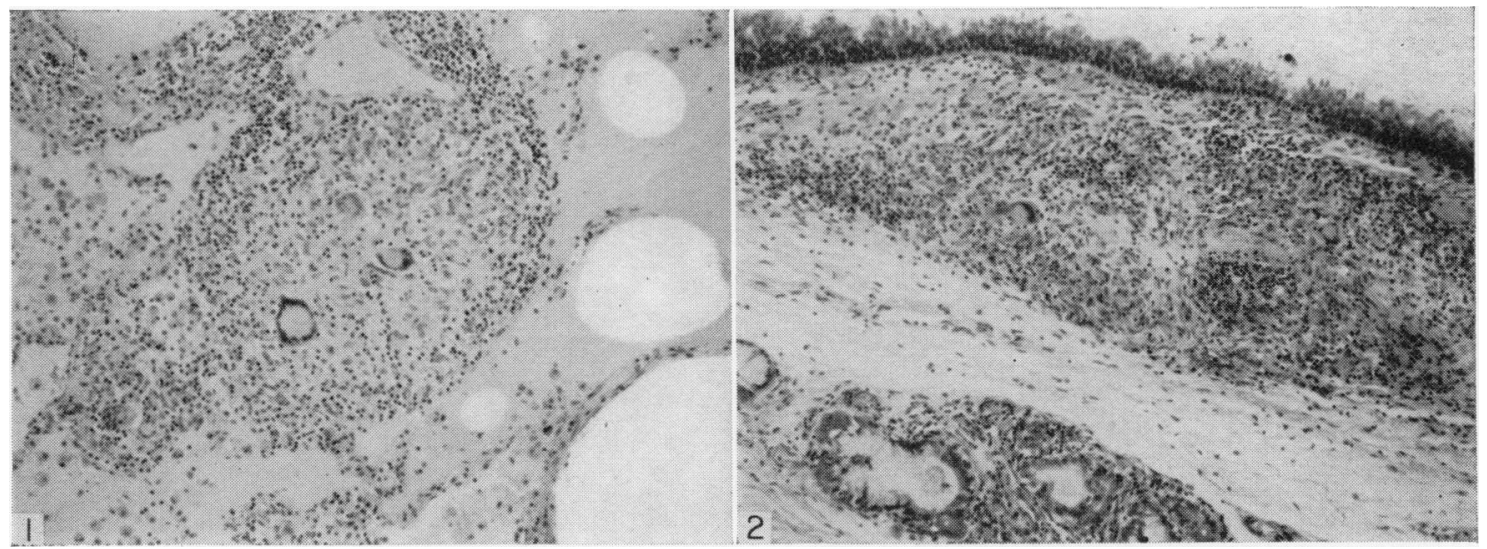

FIG. 1. Young sarcoid nodule in lung. $\mathrm{H} \& \mathrm{E}, \times 88$.

FIG. 2. Subepithelial sarcoid granulomata of vestibular larynx. H \& E, $\times 88$.

was demonstrable. The paratracheal lymph glands were very small, but the subcarinal lymph gland was considerably enlarged, measuring $4 \times 2 \times 1.5 \mathrm{~cm}$. The liver was pale and large, weighing $2080 \mathrm{~g}$. The spleen was large and congested, weighing $315 \mathrm{~g}$. The brain weighed $1670 \mathrm{~g}$. Both lateral ventricles were moderately dilated and many small greyishwhite subependymal nodules, measuring up to 1.5 $\mathrm{mm}$ in diameter, were present in the central regions and posterior horns. Both choroid plexuses contained numerous similar nodules. The third ventricle was cystically dilated, measuring $1.5 \mathrm{~cm}$ in diameter, and its surface was also studded with small subependymal nodules, measuring here abour $0.5 \mathrm{~mm}$ in diameter. The aqueduct was trumpet-shaped, measuring cranially $0.5 \mathrm{~cm}$ in diameter, and was practically occluded at its distal end by virtually confluent miliary nodules. The fourth ventricle, dura mater and leptomeninges, as well as the spinal cord, appeared to be normal.

\section{Microscopical examination (67/1307)}

The lungs are oedematous, but there is no interstitial fibrosis. Small recent sarcoid granulomata are scattered throughout the lung parenchyma (Fig. 1), and similar non-caseating nodules are present below the epithelium of the vestibular larynx (Fig. 2), trachea and main bronchi. The subcarinal lymph gland incorporates many sarcoid nodules and small numbers of similar nodules are discernible in the fibrotic paratracheal lymph glands. The spleen is congested and displays very occasional small sarcoid granulomata. The liver shows much fatty infiltration but no evidence of sarcoidosis, and no sarcoid nodules are present in pituitary, dura mater, submaxillary salivary gland, thyroid, heart, pancreas, adrenals, kidneys, bone marrow and testes.
The leptomeninges of both hemispheres and cerebellum are congested and contain typical sarcoid nodules. These are very numerous at the base of the brain, and here the non-caseating epithelioid nodules also involve the cranial nerves, being present both 'around and within the nerves. Nowhere is there any evidence of a specific arteriopathy. From the leptomeninges the sarcoid process frequently extends downward into the brain substance to a depth of a few millimetres. The small veins of both leptomeninges and brain often show dense lymphocytic cuffing, or they are completely or incompletely surrounded by non-caseating granulomata (Fig. 3). The small greyish nodules noted in lateral and third ventricles are typical sarcoid nodules. Occasionally these form large raised areas due to confluence of a number of nodules, covered by intact ependyma, but this is often superimposed by a loose fibrinous and lymphocytic exudate (Fig. 4). Many of the cerebral granulomata are surrounded by a dense zone of lymphocytic infiltrate. Both choroid plexuses are closely studded with sarcoid nodules, often confluent. The aqueduct is very dilated cranially and much narrowed distally. The tissues bordering it contain many epithelioid nodules whilst its lumen is further narrowed by a thick fibrinous exudate. Paravascular downward extension is here particularly noticeable. The spinal cord itself is intact, but sarcoid granulomata are present in the covering leptomeninges as well as next to and within posterior nerve roots (Fig. 5).

In all sites the nodular granulomata are mainly composed of epithelioid cells, with an occasional multinucleated giant-cell, and either lack central necrosis altogether or show only slight necrotic changes. Caseation is absent. Sections stained Gram, Grocott, Ziehl-Neelsen and examination in polarized light show no additional features. 


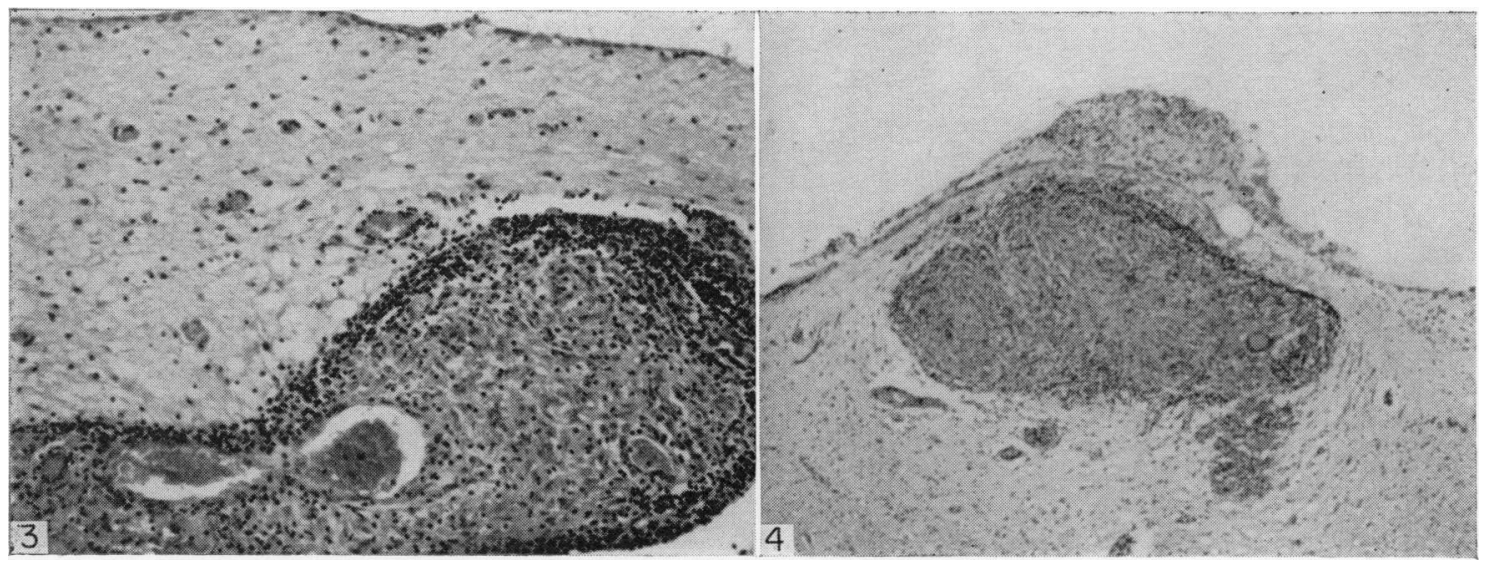

Fig. 3. Perivascular sarcoid granuloma of subependymal vein. H \& E, $\times 32$.

Fig. 4. Confluent sarcoid nodules below ependyma of lateral ventricle covered by loose fibrinous exudate. $\mathrm{H} \& \mathrm{E}, \times 40$.

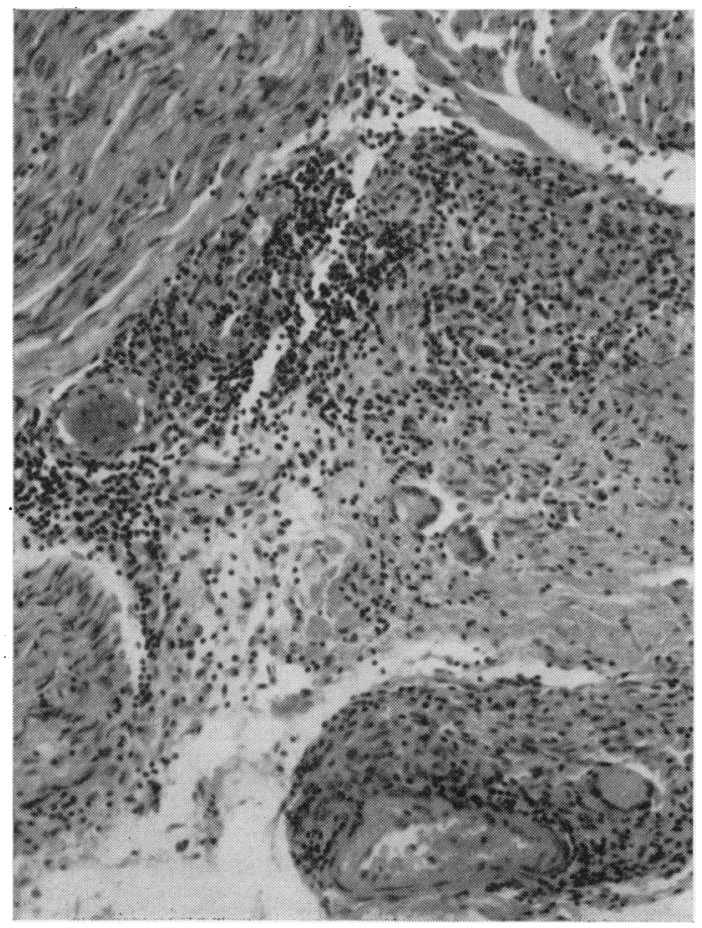

Fig. 5. Sarcoid involvement of posterior nerve roots. $\mathrm{H} \& \mathrm{E}, \times 110$.

\section{Family history}

Both parents are alive and well. There are two sisters, one of whom is healthy, the other has also been suffering from sarcoidosis (see below). One uncle by marriage, with whom the family had had much contact, suffered from pulmonary tuberculosis. He died in 1960.

\section{Patient's sister}

J.D., the patient's elder sister, was first seen in March 1962 at the age of 32 years, complaining of $\overrightarrow{0}$ increasing dyspnoea for the past 6 months. The Mantoux reaction was negative in low strengt䧄. (1:1000 O.T.), but strongly positive in higher con? centration (1:100 O.T.). Chest radiographs showed fine mottling in both lower zones and enlarged mediastinal, hilar and right paratracheal lymph glands. The ESR was $43 \mathrm{~mm}$ in $1 \mathrm{hr}$, and respiratory function tests demonstrated a diffusion defect. A left thoracotomy was carried out in April 1962 and masses of enlarged, discrete, mobile, rubbery lymph glands were demonstrated in the hilum. Microscopical examination $(62 / 1011$ and 1012) of the lingula and one of the hilar lymph glands confirmed the clinical diagnosis of sarcoidosis.

In 1963 the patient was admitted with a pulmonary infarction, a sequel to phlebothrombosis in the left leg. Prednisolone in a daily dose of $15 \mathrm{mg}$ was prescribed for her dyspnoea, but this was later discontinued as the dyspnoea had not been relieved. Liver and spleen remained impalpable.

Early in 1965 the patient's general condition deteriorated and she complained of lassitude, oedema of legs, and cervical, pre-auricular, axillary and inguinal lymphadenopathy. Both nostrils became blocked, and there was an anterior and posterior nasal discharge. In the course of 1965 the glandular swellings slowly regressed, though the nasal obstruction persisted.

By 1968 the lung fields had cleared, respiratory function tests and the ESR had become normal, 
and the patient was clinically symptomless and felt very well.

\section{Discussion}

The diagnosis of sarcoidosis in the patient and his elder sister is well substantiated both clinically and histologically. His malady started with an episode of erythema nodosum in June 1964, at the age of 27 years. There was never any evidence of pulmonary, hepatic or splenic involvement, but considerable bilateral hilar lymphadenopathy was followed by visible swelling of many peripheral lymph glands which only very gradually though eventually completely regressed over a period of 2 years. In January 1965 nasal obstruction and discharge developed due to histologically proven sarcoid involvement of the nasal mucosa. In 1966 the patient manifested a variety of cerebral symptoms and signs which continued in spite of steroid therapy. Death occurred in April 1967 at the age of 30,3 years after the onset of his illness, and was due to acute obstructive hydrocephalus. A sarcoid meningo-encephalitis was confirmed at necropsy.

The combination of familial occurrence, considerable though transient peripheral lymphadenopathy, involvement of the respiratory mucous membranes and of neurosarcoidosis is an unusual one, and these features merit separate discussion.

\section{Familial sarcoidosis}

Although a familial incidence is rare in sarcoidosis, examples in siblings have been recorded repeatedly, for example by Bickerstaff (1949), Warin (1958), Kendig, Peacock \& Pyburn (1959), Baer (1960), Quinn (1963), Allison (1964) and other familial cases are quoted by Scadding (1967). Some authors, e.g. Bickerstaff (1949), have suggested that a genetic factor affecting the individual's response to the tubercle bacillus may account for the disease entity. Others, like Scadding, doubt whether there is any significant familial liability. In Scadding's opinion, even if this were proved, it would still be doubtful whether this followed exposure to a common agent, or was due to a genetically determined response.

This view is supported by observations in the West Cornwall clinical area. Amongst fifty-four cases of sarcoidosis observed in a 6-year period there was, in addition to the present case and his sister, one other example, in two brothers, representing a familial incidence of $3.7 \%$, which does not support the idea of any particular familial susceptibility. Familial cases of sarcoidosis have always been an infrequent occurrence.

\section{Transient generalized sarcoid lymphadenopathy}

Palpable peripheral lymph glands are frequently present in cases of sarcoidosis and are a convenient means of confirming the clinical diagnosis by biopsy. However, only rarely are they of such conspicuous size as in the present case, nor do they occur as a rule so early in the course of the disease. In general the sarcoid lymphadenopathy tends to regress as other manifestations of the disease regress or disappear. The case reported is exceptional in that terminally the respiratory system, the spleen and the CNS became involved although the general stigmata of sarcoidosis had regressed and, in particular, the previously grossly enlarged peripheral lymph glands had so completely vanished that at necropsy none could be demonstrated.

Moldover (1958) observed regression of a generalized lymphadenopathy during cortisone treatment in a 24-year-old patient, which reappeared on cessation of steroid therapy and which once more disappeared on prolonged steroid administration, and similar observations were made by Baer (1960).

Sarcoid involvement of the upper respiratory mucous membrane

According to Cowdell (1954) the nasal and pharyngeal mucosa becomes involved in $10 \%$ of all cases of sarcoidosis, but case reports have not been numerous. Ricker \& Clark (1949, Case 9) briefly mention a patient with nasal obstruction. Scadding (1967) considers that involvement of the nasal sinuses, nasopharynx, larynx and trachea is rare. Three cases of sarcoid of the nasal mucosa were recorded by Dowie (1964) and Kämpfer (1964) reported involvement of the mucosa of the upper respiratory tract in $4.8 \%$ of his 227 patients. Livingstone (1956) observed involvement of the maxillary sinus. Scadding found a single case of nasal involvement amongst a series of 275 patients and mentions two further ex-series patients. Of the forty-eight cases he collected from the literature thirty-three were females.

Siltzbach \& Blaugrund (1963) took multiple random biopsies of one or more major bronchi; they obtained proof of specific granulomas in $44 \%$ of normal appearing bronchial mucosa and in $83 \%$ of patients with characteristic radiological lung changes. Random biopsies of the nasal mucosa were only positive in patients with local symptoms.

\section{Neurosarcoidosis}

In most clinical series the incidence of neurosarcoidosis has been fairly low: Ricker \& Clark (1949), 1.5\%; Cowdell (1954), $2 \%$; Goodson (1960), 1-5\%; Leading Article, Brit.med.J. (1965), 4\%; Silverstein, Feuer \& Siltzbach (1965), 4\%; Scadding (1967), $1 \%$; Wiederholt \& Siekert (1965), 3.5\%; and Kämpfer (1964), 2.2\%. However, Suchenwirth (1963) reported an incidence of $8 \%$ and James \& Sharman (1967), 7\%, and even higher percentages have been quoted (see Silverstein et al., 1965). 
Any part of the nervous system may be involved: the brain, spinal cord and nerve roots, pituitary and hypothalamus, cranial and peripheral nerves. The symptoms vary according to the site of the lesions.

In the brain and spinal cord two principal forms of presentation may be distinguished; a more or less diffuse meningo-encephalitis or meningo-myelitis and a localized pseudo-tumour due to confluence of miliary granulomata. Although the latter manifestation is rare it is clinically important as the lesion may be amenable to surgical excision (Ross, 1955; Popper, Bingham \& Armstrong, 1960; Lauschke, 1964). Pagni, Hazeghi \& Wildi (1964) carried out a hemispherectomy for sarcoid encephalopathy associated with epilepsy.

Intracranial sarcoidosis. In the brain a diffuse sarcoid leptomeningitis, usually most pronounced at the base, is a very common localization. The nodular, non-caseating granulomata tend to be about the same size and appear to be of the same age, and frequently follow the course of blood-vessels in the Virchow-Robin spaces, whence they penetrate into the adjacent brain substance, thus producing the features of a meningo-encephalitis (Simons \& Merkel, 1917; Aszkanazy, 1952, Case 1; Urich, 1967).

In some cases the walls of the cerebral vessels may be affected by the inflammatory process, either being engulfed by a non-specific lymphocytic exudate or by sarcoid granulomata (sarcoid angiopathy). Meyer, Foley \& Campagna-Pinto (1953) observed involvement of both arteries and veins associated with acute necrosis of their walls, thrombosis and infarction. Bast, Bostelmann \& Schünemann (1964) described sarcoid aneurysms of the circle of Willis, Degkwitz \& Schaefer (1965) encountered sarcoid granulomata within the walls of cerebral veins, and Urich (1967) distinguished two types of arterial lesions, an acute type with fibrinoid necrosis of the vessel walls, and a chronic type with mural erosion and obliteration of the lumen, mainly by epithelioid cells, associated with numerous areas of infarction, especially in basal ganglia, hypothalamus and pons.

The second site of predilection in the brain is the lining of the ventricles. The sarcoid nodules congregate below the ependyma, tend to coalesce, frequently forming raised whitish nodules measuring $2 \mathrm{~mm}$ or more in diameter, and fibrinous exudate may be deposited on their surfaces. Such a nodular subependymitis is liable to produce stenosis of the aqueduct, resulting in some cases in acute obstructive hydrocephalus and sudden death, and the associated fibrinous surface exudate may accelerate this process (Simons \& Merkel, 1917; Popper et al., 1960; Bast et al., 1964; Degkwitz \& Schaefer, 1965; Urich, 1967).
As there is such a definite relationship between leptomeningeal blood-vessels and sarcoid granulomata it is not surprising that, on the one hand, the choroid plexuses may be occasionally heavily involved (Simons \& Merkel, 1917; present case), whilst, on the other hand, the comparatively avascular dura mater will commonly be spared. A rare instance of dural involvement was recorded by Walker (1961, Case 1).

Involvement of the pituitary and hypothalamus may cause diabetes insipidus, and this may require replacement therapy (Cowdell, 1954; Aszkanazy, 1952, Cases 2 and 3; Bast et al., 1964; Rabendig \& Parnitzke, 1964; Morgan et al., 1965, Cases 1 and 2; Wiederholt \& Siekert, 1965). Other evidence of hypopituitarism are profound lassitude, hypothalamic obesity (Morgan et al,. 1965, Case 3), hypersomnia and lethargy (Colover, 1948), hypogonadism and loss of libido (Degkwitz \& Schaefer, 1965) and associated adrenal hypocorticism (Morgan et al., 1965).

Intrathecal sarcoidosis. Intrathecal sarcoidosis is encountered far less frequently than intracranial sarcoidosis. Aszkanazy (1952, Case 1) reported a case of meningomyelitis with destruction of nerve cells and associated ascending and descending degeneration. He observed that, as often found in the brain, the granulomata were always associated with blood-vessels, and he also noted a sarcoide granuloma within a nerve root.

In Wood \& Bream's (1959) case the nerve roots, at laminectomy, were fixed by a gelatinous adhesive process. Moldover (1958) and Silverstein et al. (1965, Case 2) recorded clinical observations of spinal sarcoidosis. Walker (1961, Case 1) reported spinal cord involvement and Williams (1967) involvement of the spinal meninges and posterior nerve roots.

Sarcoidosis of cranial nerves. Cranial nerve palsies, usually transient, have been described by many authors, for example Aszkanazy (1952, Case 5), Goodson (1960, Cases 1 and 2), Walker (1961), Morgan et al. (1965, Case 3), Silverstein et al. (1965, Cases 11-18) and Wiederholt \& Siekert (1965). The facial nerve is involved in about half of the cases of neurosarcoidosis, the lesions being unilateral in two-thirds of the cases (Colover, 1948). Other cranial nerves are affected less frequently in the following descending order of frequency: optic, glossopharyngeal, vagus, acoustic, oculomotor, trigeminal, hypoglossal, olfactory, abducens, accessory and trochlear.

Peripheral sarcoid neuropathy. Peripheral nerve lesions are uncommon and have been limited almost entirely to clinical observations. Neuritic pain is an 
important symptom and may be symmetrical or asymmetrical (Goodson, 1960). Other sensory and motor phenomena have been described. Recovery usually occurs within weeks or months, but may be incomplete, and relapses have been noted.

Silverstein et al. (1965, Cases 7-10) observed four patients with peripheral neuropathy amongst eighteen with neurosarcoidosis. Williams (1967) thought it likely that peripheral neuropathy in patients with sarcoidosis is due to the presence of specific granulomata, but only a single case with histological confirmation appears to be on record, that of Mazza (1908). He found that spindle-shaped thickenings of the median, radial and ulnar nerves were due to characteristic nodular granulomata.

Treatment and prognosis of neurosarcoidosis. Steroid treatment of neurosarcoidosis may be dramatically effective, but this is by no means invariable (Widederholt \& Siekert, 1965). Rapid improvement following therapy was observed in spinal sarcoidosis by Moldover (1958) and Wood \& Bream (1959); in acute sarcoid meningo-encephalitis by Richards (1964); and in sarcoid involvement of the hypothalamus and pituitary by Morgan et al. (1965). In other cases, however, steroids have been found to be ineffective. Walker (1961) observed great variations in the response of patients to steroid therapy, and her Case 7 gradually improved without any treatment. Silverstein et al. (1965) achieved prompt improvement with steroids in only one out of five patients with CNS sarcoidosis; of patients with cranial neuropathy one showed no improvement with steroids, five improved with therapy and two without therapy; and of patients with peripheral neuropathy two improved with steroids and two without therapy.

Wiederholt \& Siekert (1965) state that some patients die from the neurological manifestations of sarcoidosis while others are left with a permanent defect. In the majority of patients the neurological symptoms subside or show a tendency towards stabilization or amelioration. Many patients improve spontaneously. In general, according to these authors, nerve and cerebellar lesions have a good prognosis in contrast with patients with lesions of the corticospinal tract, diabetes insipidus and anterior pituitary failure.

Aszkanazy (1952) emphasizes that there is no uniform pattern in neurosarcoidosis. The malady may exhibit a benign, self-limiting course, it may show remissions, exacerbations, remain stationary for years, run a progressively declining course, or cause sudden death.

Urich (1967) distinguished between subacute and chronic types of cerebral sarcoidosis, the subacute being stormy and leading to death within 1 year, the chronic type varying from 3 to 9 years.

A sceptical view is also expressed by Scadding (1967) regarding the efficacy of steroid treatment in neurosarcoidosis, the course of which is very unpredictable. He advocates treatment only in those patients with persistent and severe symptoms and, on general grounds, considers that patients with active meningeal infiltration may be the most likely to respond to the suppressive effects of corticosteroids.

\section{Conclusion}

The case presented is remarkable in that it showed a combination of four of the less common aspects of the disease. The degree of the transient lymphadenopathy was quite exceptional and the enlarged glands caused physical disability. Involvement of the nasal mucosa is a well-known feature, but involvement of the mucosa of the vestibular larynx and of the trachea is uncommon, as are a familial incidence and neurosarcoidosis. Sarcoid granulomata in choroid plexuses and posterior nerve roots have been recorded before, but are likewise uncommon. Steroid treatment of the patient's neurosarcoidosis was unsuccessful, death being due to an obstructive hydrocephalus.

Histologically the findings in the CNS were those of a diffuse sarcoid meningo-encephalitis, subependymitis of the lateral ventricles, third ventricle and aqueduct, and specific granulomata of both lateral choroid plexuses, around cranial nerves and within posterior nerve roots. In spite of steroid treatment recent sarcoid nodules were found histologically in larynx, trachea, bronchi, lungs, hilar lymph glands and spleen.

\section{Acknowledgments}

The patients had been under the care of Dr E. W. Hughes to whom I am greatly indebted for the clinical details. Dr L. W. Hale kindly scrutinized the manuscript and my Chief Technician, Mr. W. M. Seymour, was responsible for the photomicrography.

\section{References}

Allison, J.R. (1964) Sarcoidosis. I. Familial occurrence. II. Pseudotumor cerebri and unusual skin lesions. Sth. med. J. (Bgham, Ala.), 57, 27.

AszKanAZv, C.L. (1952) Sarcoidosis of the central nervous system. J. Neuropath. exp. Neurol. 11, 392.

BAER, R.B. (1960) Familial sarcoidosis. Epidemiological aspects with notes on a possible relationship to the chewing of pine pitch. Arch. intern. Med. 105, 84.

Bast, G., Bostelmann, W. \& SchünemanN, G. (1964) Klinisch-pathologische Studie zum Krankheitsbild des Morbus Boeck mit hypophysär-dienzephaler Beteiligung. Z. Tuberk. 121, 294.

BiCKeRSTAFF, E.R. (1949) The familial aspects of sarcoidosis. Brit. J. tuberc. dis. Chest. 43, 112.

Colover, J. (1948) Sarcoidosis with involvement of the nervous system. Brain, 71, 451. 
Cowdell, R.H. (1954) Sarcoidosis: with special reference to diagnosis and prognosis. Quart. J. Med. 23, 29.

Degkwitz, R. \& Schaefer, W.H. (1965) Zur Klinik der generalisierten Boeckschen Sarkoidose mit intracerebralen Herden. Nervenarzt, 36, 70 .

DowiE, L.N. (1964) A short review of sarcoidosis, with a report of three cases with involvement of the nasal mucosa. J. Laryng. 78, 931.

Goodson, W.H. (1960) Neurologic manifestations of sarcoidosis. Sth. med. J. (Bgham, Ala.), 53, 1111.

JAMES, D.G. \& SHARMAN, O.P. (1967) Extrathoracic sarcoidosis. Proc. roy. Soc. Med. 60, 50.

K ÄMPFER, R. (1964) Über extrapulmonale Organmanifestationen des Morbus Boeck unter besonderer Berücksichtigung der Schleimhaut der oberen Luftwege. Praxis Pneumol. 18, 204.

Kendig, E.L., Peacock, R.L. \& Ryburn, S. (1959) Sarcoidosis. Report of three cases in siblings under fifteen years of age. New Engl. J. Med. 260, 962.

LAUSCHKE, H. (1964) Zur Differentialdiagnose intracranieller granulomatöser Geschwülste (Hirntumor bei Morbus Besnier-Boeck-Schaumann). Acta Neurochir. 11, 429.

Leading ARTICLE (1965) Sarcoidosis of the nervous system. Brit. med. J. 2, 316.

LivingSTONE, G. (1956) Sarcoidosis of maxillary antrum. J. Laryng. 70, 426.

Mazza, G. (1908) Über das multiple benigne Sarkoid der Haut (Boeck). Arch. Derm. Syph. (Wien), 91, 57.

MeYer, J.S., Foley, J.M. \& Campagna-Pinto, D. (1953) Arch. Neurol. Psychiat. 69, 587.

Moldover, A. (1958) Sarcoidosis of the spinal cord. Arch. intern. Med. 102, 414.

Morgan, T., Coupland, W.G., Vanderfield, G.K. \& CHURCH, D. (1965) Hypothalamic-pituitary sarcoidosis. Aust. Ann. Med. 14, 250.

Pagni, C.A., Hazeghi, P. \& Wildi, E. (1966) Boeck's sarcoidosis revealed at hemispherectomy in a case of infantile encephalopathy with epilepsy. J. neurol. Sci. 3, 76.
Popper, J.S., Bingham, W.G. \& Armstrong, F.S. (1960). Sarcoid granuloma of the cerebellum. Neurology (Minneap.), 10, 942.

QuINN, K.J. (1963) Familial sarcoidosis. J.Ir. med. Ass. 53, 161.

Rabendig, G. \& Parnitzke, K.H. (1964) Meningocerebrale form der Boeckschen Erkrankung (Klinik und Elektroenzephalogramm). Psychiat. Neurol. (Basel), 148, 84.

RichaRDS. P. (1964) Acute sarcoid meningo-encephalitis. Brit. med. J. 2, 1576.

Ricker, W. \& Clark, M. (1949) Sarcoidosis. A clinicopathologic review of three hundred cases, including twenty-two autopsies. Amer. J. clin. Path. 19, 725.

Ross, J.A. (1955) Uveoparotid sarcoidosis with cerebral involvement. Brit. med. J. 2, 593.

ScaddING, J.G. (1967) Sarcoidosis, pp. 264, 288 and 470. Eyre \& Spottiswoode, London.

Siltzbach, L.E. \& BlaUgrund, S.M. (1963). Sarcoidosis of the mucosa of the respiratory tract. Ann. Otol. (St Louis), $72,923$.

Silverstein, A., Feuer, M.M. \& Siltzbach, L.E. (1965) Neurologic sarcoidosis. Arch. Neurol. 12, 1.

Simons, A. \& Merkel, H. (1917) Zur Kenntnis der chronischen tuberkulösen Zerebrospinalmeningitis. Neurol. Centralbl. 36, 258.

Suchenwirth, R. (1963) Klinische Syndrome der Meningoenzephalitis Besnier-Boeck-Schaumann. Med. Wschr. $17,741$.

URICH, H. (1967) La Sarcoidose, pp. 591-593. Rapp. IVe Conf. Intern., Paris.

WALKER, A.G. (1961) Sarcoidosis of the brain and spinal cord. Postgrad. med. J. 37, 431.

WARIN, R.P. (1958) Familial sarcoidosis. Brit. J. Derm. 70, 250.

Wiederholt, W.C. \& Siekert, R.G. (1965) Neurologica manifestations of sarcoidosis. Neurology (Minneap.), 15, 1147.

Williams, W.J. (1967) The identification of sarcoid granu-? lomas in the nervous system. Proc. roy. Soc. Med. 60, 38.

Wood, E.H. \& BREAM, C.A. (1959) Spinal sarcoidosis. Radiology, 73, 226 